\title{
Helplessness in hippocampectomized rats: Response perseveration?
}

\author{
DAVID G. ELMES, LEONARD E. JARRARD, and PETER D. SWART \\ Washington and Lee University, Lexington, Virginia 24450
}

\begin{abstract}
In a test for learned helplessness, hippocampectomized rats, cortical controls, and unoperated controls were given shock-escape training after being subjected to a series of noncontingent shocks. During these preshock treatments, the same amount of gross body activity was elicited in all three groups. Compared to rats that did not receive the preshock treatments, all the preshocked animals performed poorly in shock escape; that is, hippocampals, cortical controls, and normals all exhibited learned helplessness. The fact that hippocampectomy resulted in the most marked learned helplessness is contrary to the response-perseveration interpretation of hippocampal function.
\end{abstract}

The behavioral changes following damage to the hippocampus are only slightly more numerous than the theories postulated to account for hippocampal function. Alterations in behavior attributed to hippocampal destruction include memory deficits (e.g., Milner, 1968), changes in response perseveration (Douglas, 1967; Kimble, 1968), and specific as well as nonspecific disturbances in motivation (Jarrard, 1973). One reason for the numerous, conflicting theories of hippocampal function is the problem associated with different amounts and localization of damage within hippocampus, the importance of which has gone unnoticed until fairly recently (Jarrard, 1973). Another reason for the theoretical imbroglio lies in the insensitivity and inappropriateness of many behavioral measures used following surgical intervention. While observations from simple runway and leverpress experiments frequently may provide insight into the functions of the physiological substrate, such studies are often not sensitive to the different aspects of behavioral change that can result from the experimental manipulation of hippocampus. Indeed, many currently popular testing procedures are unable, in their standard form, either to control for, or parcel out, confoundings such as the different levels of reactivity and integrity of memory that may arise from hippocampal intervention.

Other areas of experimental psychology have been successful in determining the aftereffects of a behavioral test by observing how experience in that test influences the behavior in a second test (e.g., Postman, 1971). Thus, with appropriate control procedures, it is possible to submit an organism to one task and then examine his behavior in a second situation-presumably, the behavior

This research was supported by NSF Grant GB-30113 to Leonard $E$. Jarrard and by funds granted to Washington and Lee University by the Sloan Foundation. We would like to thank L. W. Sanders and C. Swart for their technical assistance and D. C. Carlton for help in analyzing the data. Requests for reprints should be sent to David G. Elmes, Department of Psychology, Washington and Lee University, Lexington, Virginia 24450. resulting from prior experience evinced on Task 2 is an enduring one that is largely unaffected by local, temporary alterations in behavior such as changes in reactivity or response perseveration.

A recent experiment by Antelman and Brown (1972) nicely illustrates the use of the foregoing transfer methodology in the examination of hippocampal function. The purpose of their experiment was to determine why animals with lesions in hippocampus perform better in shuttlebox avoidance than do normal animals. Previous results from well-controlled studies suggested that the enhanced shuttlebox behavior does not result from impaired response inhibition, as argued by Isaacson, Douglas, and Moore (1961), but rather that noxious conditioned and unconditioned stimuli aroused more fear or anxiety in hippocampal rats than in normals (Lovely, Grossen, Moot, Bauer, \& Peterson, 1971). To test the fear hypothesis directly, Antelman and Brown used a transfer design in which the CS from an avoidance task was used as the CS in a conditioned-suppression paradigm. Since they did observe more conditioned suppression of drinking in hippocampals than in normals, Antelman and Brown reasoned that the avoidance task was more aversive for the lesioned than for the unoperated animals. This latter conclusion was then used to account for the superior avoidance learning evidenced by hippocampal animals.

The transfer technique seems to be a particularly sensitive one and, depending on the tasks employed, may provide some theoretical insight as the Antelman and Brown (1972) results clearly demonstrate. To assess how hippocampal rats are affected by aversive learning experiences, the present study used the learned helplessness paradigm (for reviews, see Maier, Seligman, \& Solomon, 1969; Seligman, Maier, \& Solomon, 1971). In the learned-helplessness situation, the organism is first subjected to several behaviorally noncontingent aversive stimuli (electric shock, loud noise, etc.). Following this helplessness training, the animal is placed in an escape or 
avoidance situation. Previous results show that animals who receive noncontingent aversive stimulation perform very poorly in escape or avoidance when compared to animals which were not subjected to the noncontingent aversive stimulation, and the decrement increases with increases in prior helplessness training (e.g., Maier et al., 1969). The dynamics of learned helplessness seem to involve first the learning of a null contingency between behavior and noxious stimuli, then this null contingency transfers to the escape or avoidance task where it is inappropriate. The major point at issue in the present experiment is whether or not hippocampal animals will show learned helplessness.

Previous research and theory suggest two diametrically opposed predictions concerning the ability of hippocampal rats to learn to be helpless. A first prediction, following Antelman and Brown (1972), is that hippocampals will show more learned helplessness than will normals. This is so because noncontingent aversive stimuli should be more fear- or anxiety-producing for hippocampals than for normals, which means that the hippocampal animals will learn to be more helpless than normals in the noncontingent part of the task. A directly opposite prediction seems to follow from the response-perseveration theories of hippocampus function (Douglas, 1967; Kimble, 1968). According to the response-perseveration notion, hippocampals will show much less learned helplessness than normals because the hippocampals will not learn to react passively during helplessness training (e.g., Blanchard \& Fial, 1968), and they will be unable to inhibit their responding to the aversive stimulation in the second part of the learned helplessness test. Thus, when tested for learning the null contingency, the hippocampals will, following response-perseveration theory, be more likely to escape or to avoid the noxious stimulus than will normals. The present experiment was designed to test directly these alternative predictions concerning learned helplessness in hippocampal rats by examining the shock-escape behavior of hippocampals, cortical controls, and unoperated controls following a series of noncontingent shocks.

\section{METHOD}

\section{Subjects}

Fifty-nine albino rats derived from the Sprague-Dawley strain served as subjects. They were approximately 110 days of age at the onset of the experiment. Twenty animals received lesions to hippocampus, 19 had neocortical lesions, and the remaining 20 served as unoperated controls. All animals had previous experience with food reinforcement in a straight runway under different levels of food deprivation. Prior to the present study, none of the animals had experience with electric shock or escape conditioning. All animals had free access to food and water in their home cages during the course of the experiment.

\section{Surgical and histological methods}

Operations were performed under sodium pentobarbital anesthesia $(50 \mathrm{mg} / \mathrm{kg})$. Respiratory problems were minimized by depriving the rats of water for $18 \mathrm{~h}$, then injecting $.5 \mathrm{mg}$ of atropine sulfate $1 \mathrm{~h}$ before surgery. Following a midline scalp incision, a trephine was used to remove the bone midway between bregma and lambda approximately $1 \mathrm{~mm}$ lateral to the midline. The resulting holes were enlarged to expose that part of the neocortex overlying dorsal hippocampus. The 20 rats in the hippocampal group had the hippocampus and overlying cortical tissue removed bilaterally by aspiration. A dissecting microscope was ased to help visualize the area and permitted extensive damage to be inflicted with minimal involvement of extrahippocampal structures. The 19 rats in the cortical control group had neocortical ablations similar to those in hippocampal subjects.

Following the experiment, the animals were sacrificed with an overdose of Nembutal, perfused through the heart with normal saline, and then with formalin. The brains were removed from the skull, embedded in celloidion, and sectioned at 30 microns. Cells and fibers were stained with the Kluver-Berrera stain.

Apparatus and procedure. Initially, all rats were placed, one at a time, in a standard operant-conditioning chamber with a grid floor for four 3-min periods. The control subjects, which were a random half of each operation group (10 subjects in the case of the cortical controls), merely remained in the chamber. The remaining animals, the preshock subjects, received a $60-\mathrm{V}$, 1.2-mA scrambled shock for the entire duration of each 3-min treatment. The four treatments were administered at 12-h intervals. Activity of the animals was monitored while they were in the chamber by an ultrasonic activity detector that activated a digital counter when the ultrasonic waves were disturbed by movements of the rat. Activity counts were recorded at $1-\mathrm{min}$ intervals during each treatment.

The second phase of the experiment began the day following the final treatment and involved shock-escape conditioning for all animals in a Hunter modular runway. The startbox $(30 \times 8 \times 12.5 \mathrm{~cm})$ and runway $(92 \times 8 \times 12.5 \mathrm{~cm})$ were electrified, whereas the goalbox $(30.5 \times 8 \times 12.5 \mathrm{~cm})$ was not. The shock in the startbox and runway had the same characteristics as the one used in the preshock treatments. Hunter timers measured to $.001 \mathrm{sec}$ the time taken to exit the startbox (the reciprocal of which is latency) and the running time to enter the goalbox. The latency timer started when the startbox door was raised, and it stopped when the animal interrupted a photocell beam at the entrance to the runway. Interruption of that beam also initiated the time for running speed, which was stopped when a second photobeam was broken at the entrance to the goalbox. A trial was terminated after the animal had entered the goalbox or after $60 \mathrm{sec}$, whichever came first. Animals which failed to enter the goalbox on a trial were scored as having a running time of $60 \mathrm{sec}$. Each animal received 15 shock-escape trials with a 15 -min intertrial interval.

\section{RESULTS}

\section{Anatomical}

The resulting damage to hippocampus and neocortex was comparable to that described in other research where the same surgical procedure was employed (see Jarrard, 1968); therefore, microphotographs will not be presented here. Examination of the stained sections from animals in the hippocampal group revealed extensive bilateral damage to hippocampus, especially to those pathways known to include the major efferents, e.g., fimbria and anterodorsal alveus (Raisman, Cowan, \& Powell, 1966). Although damage was less in the 
Figure 1. Mean total activity per minute as a function of treatments for each of the six groups ( $H$ indicates hippocampectomized groups; $\mathrm{CC}$ indicates cortical control groups; UOC indicates unoperated control groups).

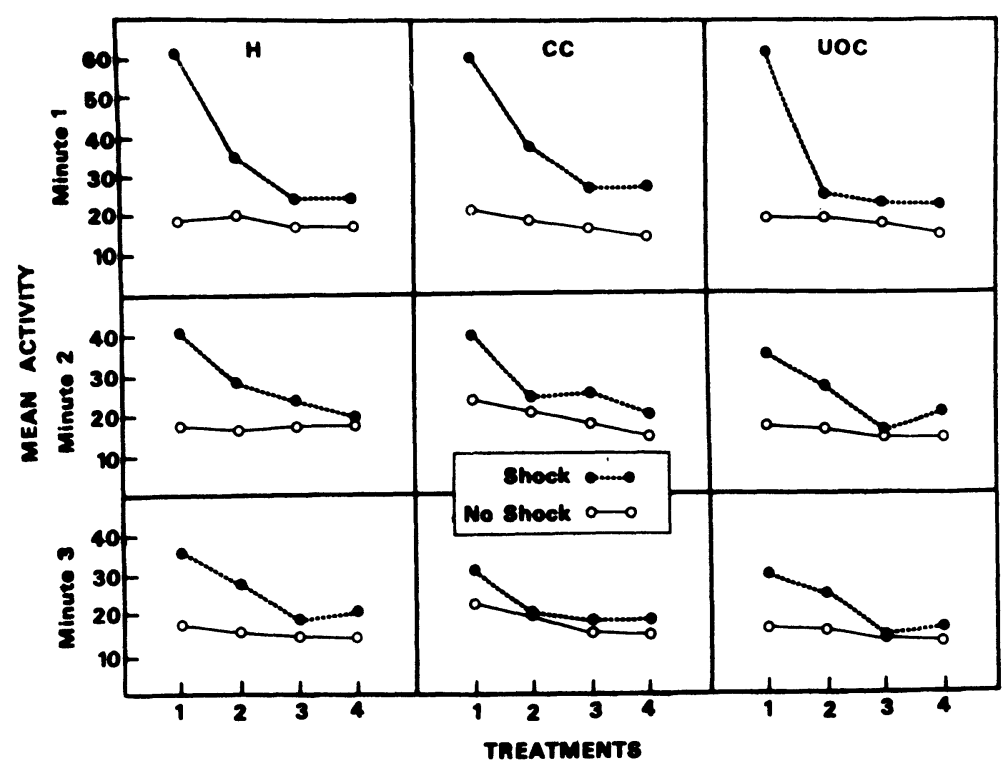

posterior alveus, there was some interruption of this recently described caudal pathway (Hjorth-Simonsen, 1973). Sparing was most evident in the posteroventral extent of hippocampus. Damage to other subcortical structures was limited to slight unilateral involvement of thalamus in three animals. Neither the extrahippocampal damage nor extent of the hippocampal lesions was found to correlate in any systematic way with activity or escape performance.

The amount of damage to neocortex and corpus callosum was similar in both cortical control and hippocampal groups.

\section{Activity}

Shown in Figure 1 are the mean activity counts per minute in all four treatments for each of the six groups. The most noteworthy aspect of those data is the remarkable similarity in patterns and levels of activity among the hippocampal, cortical-control, and unoperated-control conditions. Analysis of variance revealed that neither the main effect of operation group nor any interaction involving operation group approached conventional levels of significance, Fs $\leqslant 1.99$

While it might be reasonable to argue that the activity measure was insensitive and therefore failed to reveal differences among the operated animals, it is apparent that there were other large and systematic effects. The shocked animals were much more active than the nonshocked animals, $\mathrm{F}(1,53)=22.85, \mathrm{p}<.001$, and the level of activity decreased markedly both within, $F(2,106)=47.01, p<.001$, and across, $\mathrm{F}(3,159)=35.16, \mathrm{p}<.001$, treatments. There was a more rapid decrease in activity for the animals which received shock than for their unshocked counterparts, both within and across treatments, which resulted in the following interactions: Treatment by Shock, $\mathrm{F}(3,159)=18.07, \mathrm{p}<.001 ;$ Minutes by Shock, $\mathrm{F}(2,106)=30.62, \mathrm{p}<.001$; and Treatments by Minutes by Shock, $F(6,318)=5.42, p<.001$.

\section{Escape conditioning}

Both latency and running-speed data were analyzed, but only the latter will be reported because the two

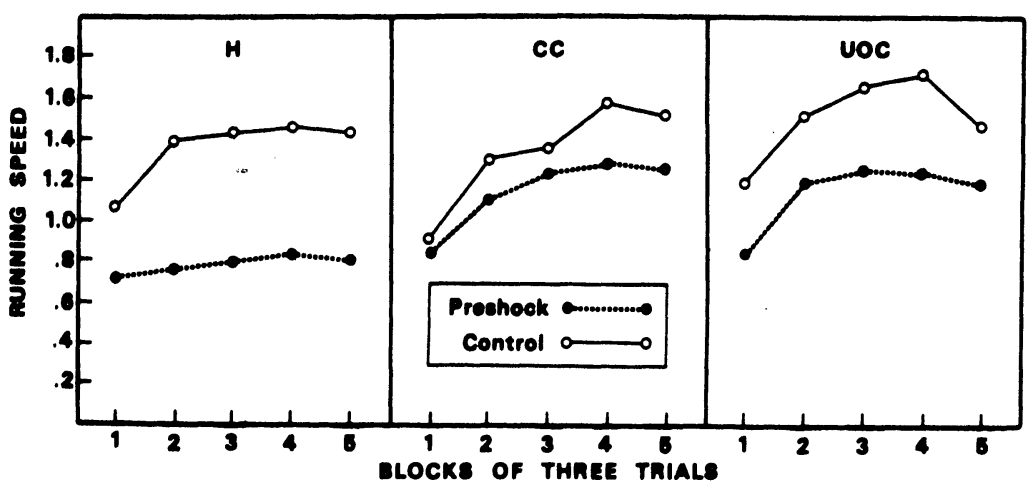

Figure 2. Mean median shock-escape running speed as a function of blocks of three trials for each of the six groups $(\mathrm{H}$ indicates hippocampectomized groups; CC indicates cortical control groups; UOC indicates unoperated control groups). 
measures indicated similar effects, and running speeds were less variable than latencies.

Shown in Figure 2 are the mean median running speeds as a function of blocks of three trials for all six groups. The dependent measure is the reciprocal of the median running time for each animal in each block of three trials.

As is apparent in Figure 2, escape conditioning was severely retarded by the helplessness training (administration of preshock). The overall escape running speed was much slower for animals who received preshock treatments than for controls who did not receive preshock, $F(1,53)=11.54, p<.005$. Learned helplessness occurred in all three operated groups, $\mathrm{F}(2,53)=1.92, \mathrm{p}>.1$, but the effect is most dramatic for the hippocampal animals. Individual $t$ tests (two-tailed) revealed that, compared to the appropriate control group, overall running speed was much slower for preshocked hippocampals, $t(18)=2.97 \mathrm{p}<.01$, somewhat slower for preshocked unoperated animals, $t(18)=1.79, p<.1$, and not reliably slower for the preshocked cortical controls, $t(17)=1.02, p>.1$.

Other than the effect of helplessness training, the only other reliable effect in escape conditioning was the increase in running speed across trial blocks, $\mathrm{F}(4,212)=25.20, \mathrm{p}<.001$.

\section{DISCUSSION}

The major results of the present experiment are empirically clear and unambiguous: (1) the gross body reactions to electric shock are the same in their frequency for hippocampals, cortical controls, and unoperated controls; and (2) rats with damage to hippocampus show marked learned helplessness. Theoretically, these results add to the increasing amount of data that bring into question the validity of the response-perseveration hypothesis of hippocampal function (e.g., recent evidence from a markedly different experimental situation is incompatible with the perseveration idea, Stevens, 1973). These theoretical implications merit additional comment.

A general theory concerned with the function of hippocampus must subsume the behavioral relationships that result from confrontation with noxious stimuli. Previous attempts to do so have centered on the apparent difficulty with which rats with damage to hippocampus have in withholding learned and unlearned responses. However, a response-perseveration theory seems incompatible with the fact that learned helplessness occurs in rats with damage to hippocampus. In order to exhibit learned helplessness, an organism must display passive behavior in the presence of a noxious event that may be terminated or avoided by an appropriate response. Such behavior does not seem typical of animals who purportedly cannot withhold learned and unlearned reactions. If anything, hippocampal animals show greater learned helplessness than do normals. Thus, it must be that hippocampals are very sensitive to contingencies between their behavior and noxious events. In the present case, the contingency was a null one; regardless of the behavior, shock still obtained. One implication of the finding of excellent learned helplessness in hippocampals is that aversive $\mathrm{Pavlovian}$ conditioning (which, in a sense, is "helplessness" learning, because the animal cannot alter the environmental contingencies to an appreciable extent) should be facilitated in hippocampal rats. Although the most straightforward test of this implication has not been conducted, some recent evidence indicates that hippocampal rats do learn to associate a CS with an aversive UCS more readily than normals (Haggbloom, Brunner, \& Bayer, 1974). Be that as it may, the current learned helplessness results are completely consistent with the notion that there is a greater arousal of fear or anxiety to noxious events in hippocampectomized rats than in normals (Antelman \& Brown, 1972; Lovely et al., 1971). This result is also congruent with the neuroendocrine findings of chronic ACTH release following damage to hippocampus and the role of high levels of ACTH in the arousal of fear and anxiety (for reviews, see Green, 1964; Mason, 1968). In the jargon of transfer of training, it is possible to summarize the learned helplessness results as follows: because the hippocampectomized rats learned the null contingency so well, there was substantial negative transfer when the contingency was changed to a negatively reinforcing one.

The present finding of a similar amount of gross body activity in response to intense, prolonged noxious stimulation also seems to be incompatible with a response-perseveration theory. One line of evidence taken as support for the response-perseveration position involves the observation that hippocampals are less likely to freeze and more likely to run than normals in response to shock (Blanchard \& Fial, 1968; Green, Beatty, \& Schwartzbaum, 1967; Schlosberg, Johnson, \& Lash, 1969). While it may be the case that there are qualitative differences in responding to shock between hippocampectomized animals and intact ones, the present results indicate that they both expend similar amounts of energy when confronted with prolonged, intense stimulation. Thus, even though hippocampals may show elevated levels of spontaneous activity and enhanced startle responses (Coover \& Levine, 1972; Jarrard, 1973), that does not necessarily mean that hippocampals must therefore exhibit greater total reactivity to intense noxious stimulation than normals. The observed similarity in activity levels bolsters the previous argument that hippocampectomy leads to enhanced learned helplessness not because of response perseveration but rather because fear or anxiety arousal 
is more intense for the hippocampectomized rat than for the intact one.

It could be argued that the passive avoidance deficits seen in hippocampals (e.g., Isaacson \& Wickelgren, 1962) are completely contrary to the fear-arousal position. After all, if the hippocampal is very fearful or anxious in the presence of noxious stimulation, then he should react quickly and appropriately to a punishment contingency. This argument is specious for two very important reasons. In the first place, Lovely et al. (1972) have demonstrated that hippocampal rats react to passive avoidance as quickly as normals once the hippocampectomized animals have had an opportunity to learn the contingency. In the second place, most studies that have compared the passive avoidance behavior of hippocampals with normals have also confounded the changes in spontaneous activity, neuroendocrine levels, and appetitive motivation (see Jarrard, 1973) that result from hippocampectomy.

Regardless of the particular interpretation of the present data, it appears that there are some implications for the mechanisms underlying learned helplessness. The inability to cope with contingent noxious stimuli following experience with noncontingent noxious stimuli has been attributed to the anxious helplessness that transfers from the noncontingent to the contingent situation (Seligman et al., 1971). It follows that the greater the fear or anxiety and learning in the noncontingent task, the greater the negative transfer to the contingent task. Previous results do in fact indicate that learned helplessness increases with such variables as amount of noncontingent training and intensity of the noncontingent shock (Maier et al., 1969; Seligman et al., 1971). Thus, strong support for the fear hypothesis of helplessness is provided by the indication that hippocampals are more anxious than normals and also show strong learned helplessness.

\section{REFERENCES}

Antelman, S. M., \& Brown, T. S. Hippocampal lesions and shuttlebox avoidance behavior: A fear hypothesis. Physiology and Behavior, 1972, 9, 15-20.

Blanchard, R. J., \& Fial, R. A. Effects of limbic lesions on passive avoidance and reactivity to shock. Journal of Comparative and Physiological Psychology, 1968, 66, 606-612.
Coover, G. D., \& Levine, S. Auditory startle response of hippocampectomized rats. Physiology and Behavior, 1972, 9 , 75-77.

Douglas, R. J. The hippocampus and behavior. Psychological Bulletin, 1967, 67, 416-442.

Green, J. D. The hippocampus. Physiological Review, 1964, 44, 561-608.

Green, R. H., Beatty, W. W., \& Schwartzbaum, J. S. Comparative effects of septo-hippocampal and caudate lesions on avoidance behavior in rats. Journal of Comparative and Physiological Psychology, 1967, 64, 444-452.

Haggbloom, S. J., Brunner, R. L., \& Bayer, S. A. Effects of hippocampal granule-cell agenesis on acquisition of escape from fear and one-way active-avoidance responses. Journal of Comparative and Physiological Psychology, 1974, 86, 447-457.

Hjorth-Simonsen, A. Some intrinsic connections of the hippocampus in the rat: An experimental analysis. The Journal of Comparative Neurology, 1973, 147, 145-161.

Isaacson, R. L., Douglas, R. J., \& Moore, R. Y. The effect of radical hippocampal ablation on the acquisition of an avoidance response. Journal of Comparative and Physiological Psychology, 1961, 54, 625-628.

Isaacson, R. L., \& Wickelgren, W. O. Hippocampal ablation and passive avoidance. Science, 1962, 138, 1104-1106.

Jarrard, L. E. Behavior of hippocampal lesioned rats in home cage and novel situations. Physiology and Behavior, 1968, 3, 65-70.

Jarrard, L. E. Hippocampus and motivation. Psychological Bulletin, 1973, 79, 1-12.

Kimble, D. P. The hippocampus and internal inhibition. Psychological Bulletin, 1968, 70, 273-283.

Lovely, R. H., Grossen, N. E., Moot, S. A., Bauer, R. H., \& Peterson, J. J. Hippocampal lesions and inhibition of avoidance behavior. Journal of Comparative and Physiological Psychology, 1971, 77, 345-352.

Maier, S. F., Seligman, M. E. P., \& Solomon, R. L. Pavlovian fear conditioning and learned helplessness: Effects on escape and avoidance behavior of (a) the CS-UCS contingency, and (b) the independence of the US and voluntary responding. In $B$. A. Campbell and R. M. Church (Eds.), Punishment and aversive behavior. New York: Appleton-Century-Crofts, 1969. Pp. 229-342.

Mason, J. W. A review of psychoendocrine research on the pituitary adrenal cortical system. Psychosomatic Medicine, 1968, 30, 576-607.

Milner, B. Disorders of memory after brain lesions in man. Neuropsy chologia, 1968, 6, 175-179.

Postman, L. Organization and interference. Psychological Review, 1971, 78, 290-302.

Raisman, G., Cowan, W. M., \& Powell, T. P. S. An experimental analysis of the efferent projection of the hippocampus. Brain, $1966,89,83-108$.

Schlosberg, A. J., Johnson, C. N., \& Lash, L. Response to shock by hippocampectomized rats. Paper presented at the meetings of the Eastern Psychological Association, Philadelphia, April, 1969.

Seligman, M. E. P., Maier, S. F., \& Solomon, R. L. Unpredictable and uncontrollable aversive events. In F. $R$. Brush (Ed.), Aversive conditioning and learning. New York: Academic Press, 1971. Pp. 347-400.

Stevens, R. Effects of amount of training on reversal learning in hippocampectomized rats. Physiological Psychology, 1973, 1, 377-379.

(Received for publication August 13, 1974; accepted September 10, 1974.) 